\title{
The Role of Antibiotics in Acute Abdominal Events
}

\author{
Shahram Manoochehry ${ }^{1}$, Hamid Reza Rasouli ${ }^{1 *}$ \\ ${ }^{1}$ Trauma Research Center, Baqiyatallah University of Medical Sciences, Tehran, Iran
}

Corresponding Author: Hamid Reza Rasouli, Trauma Research Center, Baqiyatallah University of Medical Sciences, Tehran, Iran. Tel/Fax: +98-2188053766, E-mail: hr.rasouli64@gmail.com

Received June 2, 2017; Accepted June 15, 2017; Online Published June 29, 2017

A cute abdominal events are either surgical or medical. Medical events are such as primary bacterial peritonitis and peritonitis secondary to pelvic inflammatory disease, in which usually only antibiotic administration and conservative therapy is enough. Acute abdominal surgical events are those which need surgical intervention to cure, such as acute appendicitis and secondary bacterial peritonitis. It seems that antibiotics are widely used in urgent or emergent abdominal surgical events due to current inflammation, ischemia, gangrene or stasis. In surgical events, Antibiotic administration is either prophylactic or therapeutic. ${ }^{1}$

Some studies propose only a single dose of prophylactic parental antibiotics in non-peritonitis events ${ }^{2}$ such as uncomplicated appendicitis even in atypical cases. ${ }^{3}$ For peritonitis, it is accepted to continue therapeutic

\section{References}

1. Davoodabadi A, Kashi E, Pourvali H, Akbari H. Effect of post operation antibiotic on infectious complication of suppurative appendicitis. American J Experiment Clin Res. 2018;5(1):263-6.

2. Hosseini Khalifani S, Morshedi M, Mohebi HA, Ghorbani G, Manoochehry S. Is a Single dose of Prophylactic Antibiotics Sufficient in Patients with Acute Non-Complicated Appendicitis? Hospital Pract Res. 2016;1(3):83-6. doi: 10.20286/hpr-010383.

3. Najafizadeh-Sari S, Mehdizadeh H, Bagheri-Baghdasht MS, Manoochehry S. Suppurative appendicitis presenting acute scrotal pain: a rare condition may confuse surgeons. J Surg antibiotics for a longer period. ${ }^{1}$ There are some studies that propose not only parental antibiotics but also topical irrigation with antibiotic solutions after surgical source control in secondary peritonitis to improve the overall results. ${ }^{4}$

Although there is controversy in this regard, it seems that there is an evolving progress in studies towards a less invasive more medical management of acute abdominal events. ${ }^{5}$

\section{Authors' Contributions}

SM and HRR contributed equally to this manuscript.

\section{Conflict of Interest Disclosures}

No conflicts of interest.

Funding

None.

Case Rep. 2017;2017(10):rjx215. doi: 10.1093/jscr/rjx215. pmid: 29423152.

4. Raeiszadeh M, Hoseini SMJ, Khanmohamadi MT, Manoochehry S, Rasuli HR. Comparison of Peritoneal Lavage with Normal Saline and Normal Saline Plus Antibiotic in Acute Peritonitis Patients. Trauma Mon. 2017; In Press(In Press). doi: 10.5812/traumamon.58188.

5. Georgiou R, Eaton S, Stanton MP, Pierro A, Hall NJ. Efficacy and Safety of Nonoperative Treatment for Acute Appendicitis: A Meta-analysis. Pediatrics. 2017;139(3). doi: 10.1542/peds.2016-3003. pmid: 28213607. 